\title{
Teatro de Reprise telepresencial em tempos de COVID-19
} Telepresencial Reprise Theater in COVID-19 times

\section{Teatro de Reprise telepresencial en tiempos de COVID-19}

\author{
Rosane Rodrigues ${ }^{1,4, \star}$, Eduardo Tessari Coutinho ${ }^{1,2}$, Janaína Cristina Barêa ${ }^{1}$, \\ Alexandre de Oliveira e Aguiar ${ }^{1,3}$
}

Rodrigues R (iD http://orcid.org/0000-0002-2562-8107

Coutinho E T (iD http://orcid.org/0000-0002-6254-9475

Barêa J C (iD http://orcid.org/0000-0001-5714-5751

Aguiar A O (iD http://orcid.org/0000-0003-3413-064X

RESUMO:Em tempos de quarentena da COVID-19, é essencial explorar ferramentas para enfrentar os desafios psicossociais provocados pelo isolamento social e pelas novas rotinas, além de buscar formas de satisfazer as necessidades de encontro, aproveitando os recursos tecnológicos. O objetivo deste trabalho é apresentar e discutir uma adaptação do Teatro de Reprise com recursos de telepresença. O método desenvolvido foi o de pesquisa-ação. A intervenção específica foi iniciativa de um grupo de usuários de um centro cultural, no qual se realiza regularmente Psicodramas Públicos presenciais. A partir do ponto de vista do psicodrama, este trabalho discute as implicações e as possibilidades do uso de uma plataforma tecnológica, os papéis das pessoas envolvidas e a possibilidade de novas sociometrias, em uma intervenção.

Palavras-chave: COVID-19; Psicodrama público; Grupo; Teatro de Reprise; On-line.

ABSTRACT: In times of quarantine due to COVID-19, it is essential to explore tools to face the psychosocial challenges caused by social isolation and new routines. It is worth emphasizing to seek ways for meeting the needs of getting together, taking advantage of technological resources. The objective of this work is to present and discuss an adaptation of the Reprise Theater with telepresence resources. We used the method of action research. The specific intervention was an initiative by a group of users of a cultural center, where face-to-face Public Psychodramas regularly occur. As from the psychodrama view, this paper discusses the implications and possibilities of using a technological platform, the roles of the people involved, and the possibility of new sociometries, in an intervention.

Keywords: Public psychodrama; Group; Reprise Theatre; Online.

RESUMEN: En tiempos de cuarentena del COVID-19, es esencial explotar herramientas para enfrentar los desafíos psicosociales provocados por el aislamiento social y por las nuevas rutinas, además de buscar formas de satisfacer las necesidades de encuentro, aprovechando los recursos tecnológicos. El objetivo de este trabajo es presentar y discutir una adaptación del Teatro de Reprise con recursos de telepresencia. El método desarrollado fue el de investigación-acción. La intervención específica fue iniciativa de un grupo de usuarios de un centro cultural, en el cual se realizan regularmentePsicodramas Públicos presenciales. A partir del punto de vista del psicodrama, este trabajo discute las implicaciones y las posibilidades del uso de una plataforma tecnológica, los papeles de las personas involucradas y la posibilidad de nuevas sociometrías, en una intervención.

Palabras-clave: COVID-19; Psicodrama público; Grupo; Teatro de Reprise; Online.

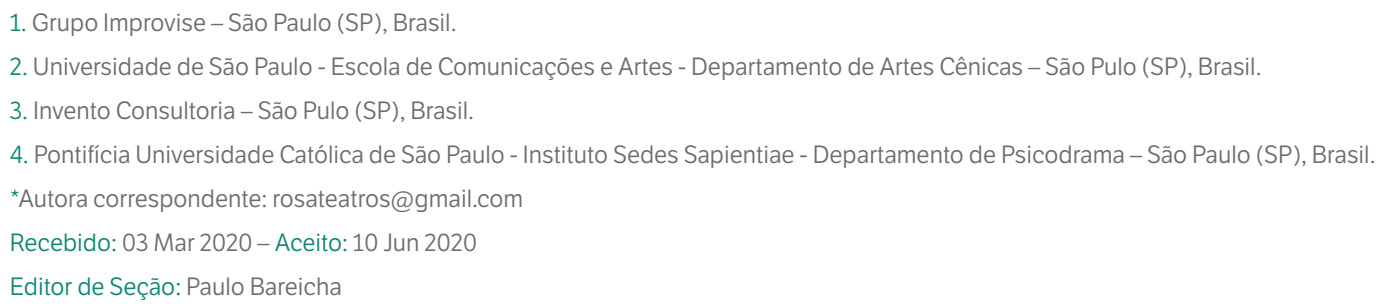




\section{INTRODUÇÃO}

Em março de 2020, a Organização Mundial da Saúde (OMS) caracterizou a epidemia de COVID-19 como uma pandemia. Como consequência, a maioria dos países passou a implantar medidas de distanciamento social em vários níveis e modalidades, visando limitar a transmissão do vírus e evitar o colapso em seus sistemas de saúde.

Vale esclarecer que o distanciamento social é caracterizado como uma medida para a redução da disseminação do contágio; o isolamento social é recomendado como única alternativa de prevenção conhecida de contágio. Trata-se de medidas que devem ser tomadas caso alguém tenha tido contato com pessoas contaminadas ou sintomáticas. Como este relato apresenta uma intervenção realizada na cidade de São Paulo, o epicentro da epidemia no Brasil, as medidas de distanciamento aqui referidas serão compreendidas como quarentena, devido ao grande número de casos suspeitos e confirmados na cidade.

As ações tomadas pelos governos municipal e estadual, de maneira geral, implicaram em mudanças importantes no dia a dia das pessoas. Isso incluiu temas como: ficar em casa o máximo possível, fechamento temporário de estabelecimentos de ensino, de diversos tipos de comércios e outros negócios não-essenciais, e, em outros casos, a realização de trabalhos à distância ou a entrega de produtos nas modalidades de delivery ou take away. Do ponto de vista político, as reações das pessoas são diversas e incluíram, por exemplo, a defesa veemente ou a crítica contumaz às medidas de distanciamento social. De outro lado, surge o contato diário com a necessidade de lidar com o risco, com a morte (real ou potencial), com a solidão, desencadeando iniciativas de solidariedade, assim como confrontos violentos entre grupos.

A impossibilidade dos encontros, dos eventos sociais, dos espaços de lazer coletivo e de rituais, causa impacto significativo para a saúde mental, provocando grande sofrimento psíquico (Brooks et al., 2020). Marcinko et al. (2020) alertam para a necessidade de uma abordagem psicodinâmica otimizada para a aceitação do estresse psicológico de uma maneira mais positiva.

Ruiz, Arcaño e Pérez (2020) chamam a atenção para as especificidades da pandemia e para a necessidade de se compreender as relações entre as dimensões psicológica e social com outras dimensões da pandemia. A expressão cênica pode ser usada para lidar com a crise, e Mindoljević e Radman (2020) recomendam que o psicodrama deve levar em conta cuidados para a prevenção em relação ao protagonista, ao reviver o trauma, por meio da ativação de papéis novos e transformadores.

Do ponto de vista das atividades clínicas, os conselhos profissionais de medicina e psicologia regulamentaram temporariamente, durante a pandemia, a telemedicina e a psicoterapia à distância. No caso da prática psicodramática em geral, e do Teatro de Reprise em particular, foi necessário adaptar-se aos recursos tecnológicos de telepresença, streaming e outros recursos. Fleury (2020), em editorial da Revista Brasileira de Psicodrama, chama a atenção para aspectos importantes sobre o telepsicodrama tais como a necessidade de: se desenvolver novas competências de comunicação e habilidades no uso de tecnologia; aspectos éticos como consentimento informado, segurança da informação e privacidade; e o desenvolvimento de recursos para a dramatização.

O Teatro de Reprise (TR) é uma modalidade de psicodrama (Rodrigues, 2016) que tem sido utilizado em ambiente corporativo, institucional e comunitário, tradicionalmente na modalidade presencial. Inspirado no Playback Theatre (Salas, 2000), o TR caracteriza-se, fundamentalmente, por colocar no palco cenas vividas por narradores voluntários que não atuam no palco, como os protagonistas clássicos do psicodrama, mas que têm a oportunidade de assistir a cena recriada e ressignificada por uma equipe profissional permanente, formada por ego-atores e ego-músicos. O TR apresenta, portanto, desafios adicionais para a realização de maneira "remota", dadas as diferenças entre a linguagem teatral e a linguagem audiovisual. Além das dificuldades advindas da falta de recursos inerentes a esta linguagem audiovisual, tendo em vista que a intervenção é improvisada e a partir do "dar voz ao grupo de participantes". 
Diversos autores descrevem experiências de ensaios e de apresentações teatrais em ambientes de telepresença. Gorman, Syrjä, e Kanninen (2019) relatam a criação de dois espaços físicos idênticos visando dar a impressão de que os atores estavam no mesmo espaço. Relatam o uso de ferramentas digitais de apoio, tais como o Facebook, para comunicação ágil, compartilhamento de material e reuniões virtuais, e o Adobe Connect, para a criação de ambientes específicos de ensaio. Os autores chamam a atenção para a necessidade de desenvolver e experimentar alternativas sensoriais ao toque, as quais não estão presentes no trabalho em sua modalidade virtual. Kaiser, Ursu, Falelakis, e Horti (2015) apresentam o conceito de "teatro distribuído", em que a ação ocorre em dois ou mais palcos, e consideram que para uma experiência verdadeiramente imersiva é essencial que se possa, dinamicamente, reenquadrar as câmeras e misturar os conteúdos.

Freeman (2019) descreve, em sua experiência com teatro em plataforma de streaming, que uma das dificuldades é que a plateia não se engaja tanto quanto se estivesse no mesmo espaço físico dos atores, como é no teatro presencial.

O objetivo deste trabalho é apresentar uma experiência de TR desenvolvido especificamente para o ambiente de telepresença. O artigo descreve, nas seções seguintes, o método utilizado como pesquisa para o seu desenvolvimento, a experiência vivida pelo grupo na realização de uma intervenção de TR on-line, além de discutir os resultados, as lições aprendidas e as perspectivas.

\section{MÉTODOS E TÉCNICAS}

\section{ABORDAGEM METODOLÓGICA}

A pesquisa de novos métodos, ou adaptações de métodos, ou protocolos existentes se posiciona no âmbito da pesquisa aplicada, em que se busca encontrar soluções para problemas reais. Nas áreas de conhecimento ligadas às ciências sociais aplicadas, a pesquisa-ação éum dos métodos de referência. Moreno, criador do psicodrama, foi precursor da pesquisa pela ação com o observador participante, que é parte integrante do pensamento e da postura psicodramática. Segundo Tripp, a pesquisa-ação se caracteriza por ser uma “. . . forma de investigação-ação que técnicas consagradas de pesquisa para informar a ação que se decide tomar para melhorar a prática ..." (2005, p. 447). Este autor caracteriza a investigação-ação como um processo em que se aprimora a prática transitando entre o agir no campo da prática e o investigar a respeito da própria prática. O ciclo de aprimoramento é mostrado na Fig. 1. A pesquisa-ação se diferencia de outros processos de investigação-ação porque tem como característica essencial a participação dos usuários daquilo que precisa ser melhorado como agentes da pesquisa, desde a definição de objetivos até as conclusões.

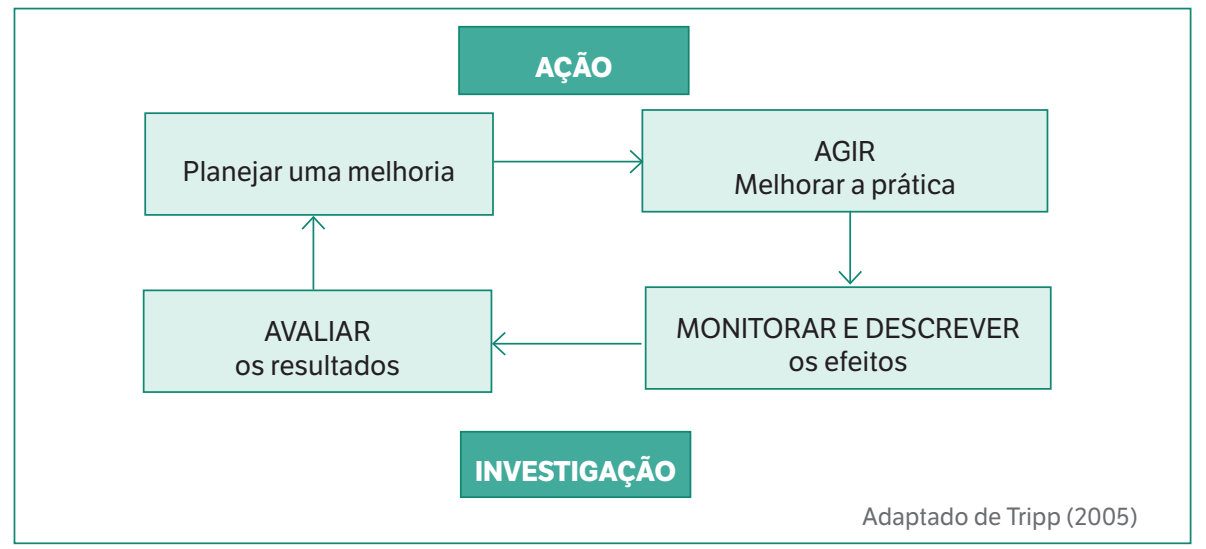

Figura 1. Ciclo investigação-ação. 
A pesquisa-ação se caracteriza por uma intensa relação entre o pesquisador e o contexto social no qual o problema ocorre, e mesmo pela imersão do pesquisador nesse contexto. Nesse sentido, o processo de desenvolvimento de um protocolo adaptado do Teatro de Reprise para o ambiente on-line, realizado por pesquisadores que são membros da trupe que faz essa adaptação, caracteriza-se como pesquisa-ação.

\section{O CONTEXTO DA PESQUISA}

O Grupo Improvise é uma trupe que pratica o Teatro de Reprise desde 2001. O grupo é formado por psicodramatistas, estudantes de psicodrama, atores e músicos. Além disso, os componentes possuem formação variada, como psicologia, educação física, artes cênicas e engenharia, o que traz uma riqueza de experiências e habilidades de formação. No momento em que se realizou este trabalho, o Grupo era composto por doze membros entre ego-atores e ego-músicos, com variado tempo de experiência na linguagem.

Desde a sua criação, o grupo sempre praticou o Teatro de Reprise presencial, sem o uso de grandes tecnologias, com algumas exceções. Como exemplo, há exato um ano, foi feita uma experiência do Grupo Improvise com o Teatro de Reprise por meio de uma rede social em tempo real, mas foi abandonada por falta de recursos técnicos e motivação. Assim como a maioria das pessoas e grupos, durante a pandemia da COVID-19, o Grupo teve que se reinventar e se viu desafiado a encontrar um meio de fazer o Teatro de Reprise em ambiente virtual.

O TR, como modalidade, segue os princípios do psicodrama, assim como as etapas rituais (aquecimento, dramatização, compartilhamento) e a busca da espontaneidade.

Até o período da pandemia, a única plataforma usual de comunicação do grupo era o aplicativo WhatsApp. Mas, o momento pediu o uso de tecnologias mais abrangentes para que pudéssemos continuar apresentando o TR.

Vários ensaios foram feitos para explorar os recursos tecnológicos da plataforma Zoom - versão profissional, escolhida pelo grupo para a realização do TR on-line. Após estudos realizados pelo grupo nessa plataforma, bem como a escolha da linguagem a ser utilizada, foram realizados dois ensaios abertos para convidados e, posteriormente, foram realizados dois eventos para plateias abertas.

O segundo evento foi realizado para um grupo específico de usuários do projeto de Psicodramas Públicos do Centro Cultural de São Paulo (CCSP) e alguns psicodramatistas. Há muitos anos esse grupo de usuários participa regularmente do projeto que acontece aos sábados, organizado voluntariamente por uma equipe de sustentação, composta de psicodramatistas. Com o advento da COVID-19, os eventos presenciais foram interrompidos. No entanto, os usuários desse projeto, que existe há dezesseis anos, se organizaram e escolheram uma plataforma digital, depois acionaram a equipe organizadora dessa atividade para que retomassem on-line os encontros com o público participante e outros convidados. Então, a equipe organizadora realizou por duas semanas seguidas o psicodrama on-line e convidou o Grupo Improvise para a realização da terceira intervenção.

\section{PASSOS METODOLÓGICOS}

O ciclo de investigação-ação foi "rodado" várias vezes ao longo do processo:

a. Planejamento: inicialmente, foram realizados testes, reuniões e ensaios preliminares utilizando-se as plataformas Zoom e Google Meet. Entre estas duas, o Zoom destacou-se pela qualidade da imagem ao apresentar 25 participantes em 
uma mesma sala, e pela possibilidade em separar os ego-atores em uma sala independente. A Fig. 2 mostra um exemplo de como os participantes aparecem na tela do aplicativo.

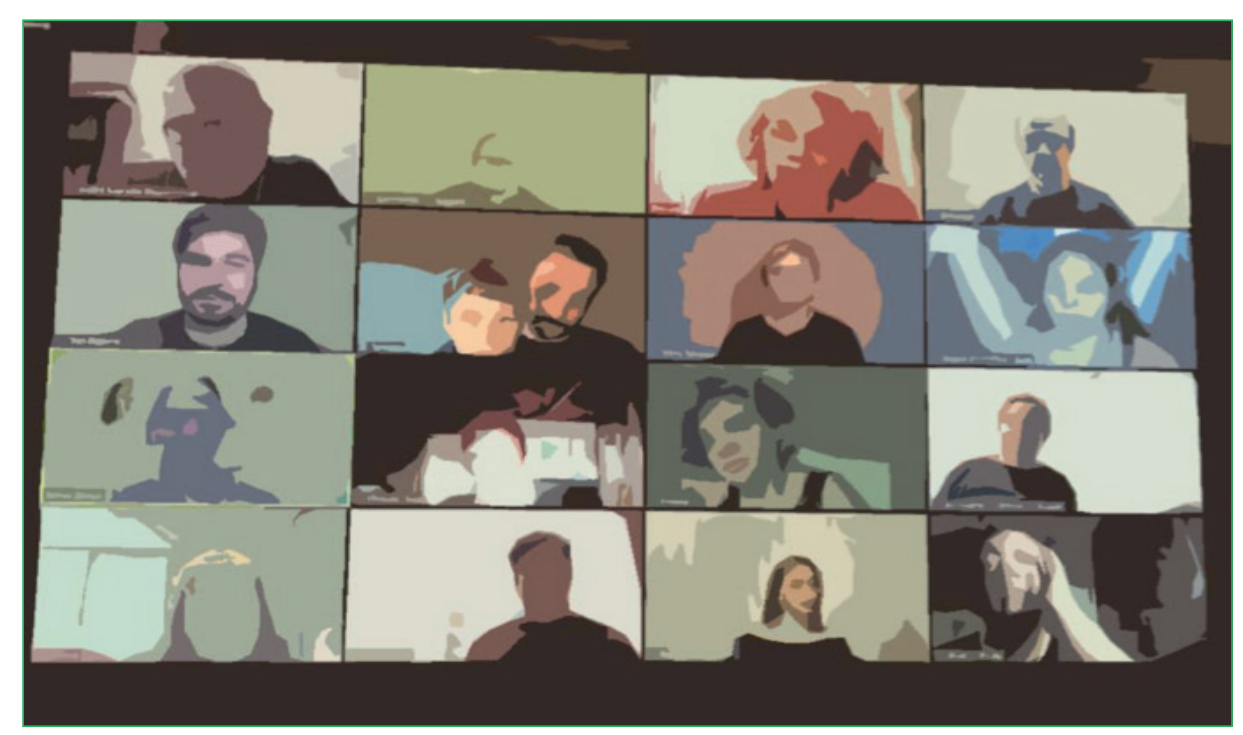

Figura 2. Exemplo de tela do aplicativo Zoom

O pacote escolhido apresenta as seguintes ferramentas:

- Os participantes podem ligar/desligar o próprio áudio e vídeo; e o “anfitrião" também tem acesso a esses comandos em todos os participantes;

- A possibilidade de separar os participantes em "salas";

- Mensagens escritas em "bate-papo” (chat), tanto para todo o grupo quanto para participantes específicos;

- Levantar a mão para pedir a vez de se manifestar;

- Recursos de "emoji”, tais como "bater palmas" e fazer "ok";

- Funciona em diversos sistemas operacionais, como Windows, Android, iOS e Mac;

- $\quad$ No Android aparecem no máximo quatro janelas - a própria pessoa e mais três;

- $\quad$ No computador aparecem até 25 janelas por tela;

- O pacote contratado permite até 100 participantes;

- $\quad$ Fazer enquete.

b. Ensaios para convidados: foram realizados dois ensaios para convidados. O primeiro com dois e o segundo, com seis convidados. Cada ciclo de ensaio incluiu o planejamento, a execução do ensaio, o registro do resultado e a análise da melhoria, seguindo o ciclo de investigação-ação. Registro por meio de gravação de resultado e análise da melhoria foram realizados imediatamente após os ensaios, usando a própria plataforma de comunicação.

c. Sistematização do conhecimento: os ensaios e as intervenções proporcionaram a criação de conhecimento, e as lições aprendidas foram compartilhadas entre os membros do Grupo, e é no presente artigo que esse conhecimento é sistematizado criticamente. 


\section{UMA INTERVENÇÃO NA QUARENTENA}

Segundo Monteiro, Merengué e Brito (2006), Moreno foi o pioneiro no uso de transcrições integrais, como a que é apresentada a seguir: então, passemos a ela.

A diretora do Grupo Improvise foi convidada por Mariângela Wechsler, uma das organizadoras dos Psicodrama Públicos do CCSP, a se apresentar no dia 16/05/20 no horário das 10h30 da manhã até 12h30. O trabalho foi realizado utilizando a modalidade de intervenção do Teatro de Reprise. O Grupo Improvise foi composto por: uma diretora, um anfitrião/mediador (responsável pela coordenação técnica do trabalho e explicação do uso da plataforma aos participantes), uma coanfitriã (responsável por responder e possibilitar o cuidado por meio do bate-papo (chat), três ego-atores e dois ego-músicos.

Para a realização do trabalho, o Grupo Improvise fez apenas a exigência da utilização da sua conta na plataforma Zoom, pela familiaridade adquirida nos ensaios e na apresentação anterior.

O trabalho teve a participação de um público aproximado de cinquenta pessoas. A intervenção iniciou com a organizadora do projeto apresentando a diretora e abrindo os trabalhos do dia. Em seguida, o anfitrião/mediador deu as orientações gerais sobre o uso da plataforma.

A diretora apresentou cada membro do Grupo Improvise e suas funções, e convidou a todos para escutar a música "Quando a chuva passar" (de Ramon Barreto Cruz, famosa pela interpretação de Ivete Sangalo) cantada a capela pelos ego-músicos do grupo.

Após a música, a diretora identificou uma participante que não conhecia o psicodrama e deu explicações gerais sobre a intervenção. Feito isso, solicitou aos participantes que procurassem um objeto ou uma roupa em casa que expressasse suas emoções nessa quarentena e que, se preferissem, deixassem a câmera desligada durante a busca. Posteriormente, ela solicitou que todos desligassem as câmeras e que só permanecessem ligadas as pessoas que estivessem de posse do objeto requisitado. A seguir, foi realizado um mapeamento sociométrico, categorizando as possíveis emoções vividas durante a pandemia e relacionadas ou não com o objeto escolhido: emoções desagradáveis como medo, raiva e frustração; e a outra categoria emoções prazerosas, como descobertas, novos projetos etc. Depois disso, os participantes foram convidados a compartilhar suas emoções, um de cada vez, para que os ego-atores realizassem esculturas fluidas (Salas, 2000; Rodrigues, 2016) que, neste caso, por se tratar de uma intervenção on-line, foram sequências fluidas (Rodrigues, 2016). As emoções expressas pelo público foram: ambivalências (turbilhão de emoções); saudade (dos amigos); alegria (encontro com o feminino); resiliência (algo bom de transformação); medo; prazer; conexão; reflexão; raiva vs. carinho; acolhimento vs. rejeição; e, potência vs. impotência.

$\mathrm{Na}$ fase de mergulho no conflito foi realizada a fantasia dirigida (Rodrigues, 2016), na qual a diretora solicitou que fechassem os olhos e que recordassem as cenas do que estariam vivendo nesses tempos de pandemia ou que surgissem livremente. No ciclo do diálogo intercênico (Rodrigues, 2016), a primeira cena foi a de uma mulher que narrou a interrupção de suas primeiras aulas de pandeiro, pelo qual estava se apaixonando, devido à pandemia. Ela disse que se sentia roubada.

Durante a combinação da cena, inspirados na cena da narradora, os ego-músicos cantaram "A Rita" (Chico Buarque) e "Malandragem" (Frejat/Cazuza).

Os ego-atores realizaram a cena de modo que um ego-ator representava a narradora. Foram quatro momentos dispostos em quatro telas: na primeira, apenas uma mão aparece batucando no pandeiro; na segunda tela, a narradora diz gostar, mas sem entusiasmo. A cena se repete uma segunda vez e a narradora se entusiasma mais. Na terceira repetição, a narradora fica exaltada e feliz. Na terceira tela, o terceiro ego-ator aparece como um ladrão que, usando um capuz de esquiador e com 
movimento suspeito, "roubava o pandeiro" usando o movimento de "pegar algo" perto da câmera, fazendo com que o pandeiro sumisse da outra tela. A narradora termina frustrada e faz o discurso de se sentir roubada.

A segunda cena foi a de um homem que narrou um sonho no qual ele era uma pessoa pobre que estava passando fome e resolve, junto com outros, saquear a casa dos corruptos para pegar comida. Era, então, reprimido pela milícia desses corruptos. $O$ que o fez recordar-se da juventude, quando também apanhava do aparato policial durante a ditadura militar, em protestos às ruas.

Durante a combinação da cena os ego-músicos cantaram “Pra não dizer que não falei das flores” (Geraldo Vandré) e “Volte para o seu lar" (Arnaldo Antunes). Uma das participantes do grupo pediu permissão e compartilhou, pelo Zoom, uma fotografia da paisagem de prédios tirada de sua janela naquele momento, enquanto os ego-músicos cantavam.

Para a realização da cena os ego-atores se dividiram em: um era ele atual, que iniciava a cena contando como havia feito há pouco, e congelava. Em seguida o outro, que era ele no sonho, falava da fome e da decisão de saquear, e congelava. O ele atual falava da lembrança da juventude, e congelava. O ele na passeata começava a fazer os gritos de protesto da época, e congelava. Em seguida os três, ao mesmo tempo, fizeram movimentos em câmera lenta como se estivessem apanhando.

Na etapa do compartilhar, as pessoas elogiaram muito o trabalho e disseram terem sido afetadas, mesmo com a distância e a intermediação pelo recurso tecnológico. Foram colhidas no bate-papo (chat) algumas frases espontâneas como: "Lindo trabalho!”, “Excelente trabalho!”, “Maravilhoso trabalho!”, “Tudo formidável”, “agradeço muiiiiito a todos! muito especial!”. E uma frase, que mostra que a apresentação on-line conseguiu a mesma potência da presencial, foi colocada por uma das participantes: "sempre me emociono".

Em momentos posteriores à intervenção, algumas pessoas manifestaram surpresa quanto ao grau de envolvimento e de emoção proporcionados pelo método, até porque eram céticos quanto ao potencial do uso de ferramentas digitais no psicodrama.

A pessoa que trouxe o tema da saudade dos amigos na escultura fluida compartilhou "alívio". Uma das narradoras do pandeiro compartilhou o "privilégio de ter casa e poder fazer a quarentena com certa tranquilidade" e o "privilégio de ter estado no evento".

Mariângela Wechsler, que convidou o Grupo Improvise, fez um lindo texto com trechos das músicas tocadas no evento, se dizendo emocionada. Vários participantes marcaram que tinham certo preconceito de coisas feitas on-line e que se surpreenderam com a possibilidade da emoção que sentiram. Outros comentaram que aprenderam sobre a plataforma. Um dos participantes leu um trecho do conto Felicidade clandestina, de Clarice Lispector. A diretora disse que havia separado um texto que acabou não usando, mas que combinava com esse: José, poema de Carlos Drummond de Andrade, do qual leu somente a primeira estrofe. Alguém mencionou o trecho de uma música: “Vocês me prendem vivo e eu escapo morto!" (trecho de "Pesadelo", de Maurício Gomes e Paulo Cesar Pinheiro).

\section{REFLEXÕES SOBRE A INTERVENÇÃO}

Um dos destaques dessa intervenção foi o chamamento do público assíduo do CCSP para que esse projeto, já reconhecido internacionalmente (Wechlsler \& Monteiro, 2014), fosse retomado. A comunidade psicodramática paulistana conta com um grupo de sustentação voluntária, do qual uma das autoras participou por quinze anos, na organização desses encontros que dá "voz" e vez para muitas pessoas que não encontram, na cidade, a oportunidade de serem sequer vistas, quanto mais ouvidas pela sociedade. Um trabalho de cidadania dos mais exitosos do psicodrama brasileiro que mostra que fincou raízes por meio de seus usuários. 
Quanto a intervenção em si, o aquecimento vincular com foco na plateia (Rodrigues, 2016) contou em seu início com instruções técnicas no uso da plataforma, o que pareceu facilitar grandemente o uso dos participantes durante todo o processo. Além da apresentação entusiasmada da organizadora do projeto. Alguns, na fase final de compartilhamento, comentaram espontaneamente que tinham preconceito contra o psicodrama ou ações desse tipo on-line, e que aprenderam muito e ficaram mais íntimos dessas tecnologias. Os estudos que fizemos, mencionados acima na metodologia, para entender e dominar os recursos da plataforma possibilitaram ao anfitrião/mediador transmitir segurança e facilidade aos participantes em linguagem simples e direta. Houve um comentário posterior de que esta etapa acolheu e ajudou no aquecimento para o trabalho.

As adaptações do TR realizadas pelo Grupo Improvise para a linguagem on-line resultaram em facilidade para os participantes, assim como para a própria equipe de trabalho, que não encontraram obstáculos importantes para ver e ouvir tudo o que se passava na intervenção. Além disso, os anfitriões técnicos cuidaram daqueles que tinham dificuldade com o acesso, ou mesmo os que não desligavam o microfone ou o vídeo quando era preciso. Um ganho grupal significativo, na perspectiva psicodramática, assim como na perspectiva cidadã. Ou seja, alguns dos participantes tinham, sim, um estranhamento com a tecnologia, porém, reduzido ao mínimo pela equipe para que pudessem se entregar ao processo não racional do tema, isto é, de como estávamos vivendo esse momento de quarentena.

Notamos que a fluência para que a emoção dos participantes ocorresse, que era truncada no início de nossas experiências de ensaios com o uso da plataforma, nesse momento da intervenção adquiriu potência e ritmo, afetando a muitos em vários momentos. Isso promoveu, na intervenção, instantes plenos de campo intensivo focado, o que Féo chama de "instantes protagônicos" (2009, p. 94). A fluência foi atingida como o resultado de um aquecimento eficiente, no início, e a manutenção por parte da equipe, e do estabelecimento de um contrato coconsciente (CCS) claro, criando possibilidades de um coinconsciente (CICS) favorável ao trabalho.

Esse CICS já existia no Grupo Improvise e em parte do grupo de participantes, e foi mobilizado para os objetivos comuns do dia, adensando o caldo de comunicações grupais, que é desejado nesse tipo de intervenção. Cabe ressaltar que na intervenção ocorre um contágio, já definido por Rodrigues (2016), do CICS da equipe permanente de trabalho e dos grupos pré-existentes, que se adensam para criar um campo de forças para o surgimento dos conflitos em comum do grupo, sem qualquer racionalidade. No caso, a quarentena e a vida cotidiana abalada e transformada para algo disruptivo, com aspectos considerados bons ou maus conforme cada um dos participantes. A criação de um campo télico, ou seja, de saúde, é o objetivo permanente.

Os objetos trazidos pelos participantes expressando suas emoções desagradáveis ou prazerosas foram curiosos. Esses objetos foram: quadros simbolizando o privilégio de terem casa e poderem ter conforto que outros não têm; cristais preciosos mostrando o entusiasmo de estar junto; também surgiu uma estátua simbolizando a descoberta do feminino e da boa companhia de si mesma nesse momento de reclusão e solidão de uma mulher.

As emoções relatadas pelas pessoas no aquecimento dramatúrgico da plateia, na fase descristalizadora, por meio das esculturas fluidas (primeiras ressonâncias estética), falam especificamente de como se sentem em relação à pandemia, não aparecendo o assunto da tecnologia. Ou seja, o grupo de participantes só contou de turbilhão de emoções, de medo, prazer, reflexão, contato consigo mesmo, raiva de arbitrariedades e violência, potência, impotência, rejeição e acolhimento, além da saudade de ver os amigos. Esta última foi referida ao final da intervenção como um alívio por ter encontrado com amigos naquele setting. Lembrar que vários desses participantes se conhecem e, quando os psicodramas públicos ocorrem, alguns se encontram todas as semanas. 
Esse sociodrama na modalidade TR conseguiu, mesmo com as barreiras tecnológicas e com a falta de intimidade de alguns com essa linguagem, atingir um ritual iniciático de encontro com o conflito comum semelhante ao que costumamos atingir, enquanto equipe, nas intervenções presenciais.

A primeira cena surgida na etapa de ação dramática nos contou a frustração da narradora com o projeto, que estava no início, mas que já despertava uma grande paixão: a aula de pandeiro. Ela foi bruscamente interrompida pela quarentena, assim como muitos projetos dos presentes que, apesar de necessária, nos isolou, impossibilitando continuar vivendo como vivíamos. Algo simples, como aprender um instrumento e ter autonomia sobre a própria vida e os próprios projetos. O pandeiro era emprestado, e ela precisou devolver. Simples assim. Também, não podia sair para comprar outro pandeiro pois não havia pandeiros à venda. Não há como seguir vivendo projetos novos ou plenos. Toda a vida de todo o planeta está em suspenso, como a vida de cada um com as suas especificidades.

A segunda cena no diálogo intercênico "conversa" com essa dor e destaca muita revolta e raiva tornando o sonhador/ narrador um ativista que busca justiça quebrando sua própria ética, tal o teor do sofrimento. Ele se recorda de passeatas contra os tempos de exceção, como os da ditadura militar, em que arbitrariedades e violência foram cometidas com o propósito de reprimir nossa "voz".

O clima da nossa intervenção, no entanto, era de liberdade para se expressar o que se quisesse, a ponto de uma participante, durante a combinação dos atores em outra sala, ter proposto colocar, pelo Zoom, uma fotografia, logo no início da música. Da janela de sua quarentena, os prédios e a beleza da paisagem, era o que queria compartilhar. Ou seja, certo bem-estar que estava sentindo durante o trabalho e a quarentena.

A cada espelho ressonante (Rodrigues, 2016) realizado pelos ego-atores num palco recriado virtualmente, em que cada ator está isolado em outro ambiente do colega de Grupo, o clima de forte emoção era realinhado com os participantes, intensificando o campo protagônico já referido. Notar que os ego-atores ficaram por algum tempo em outra sala virtual combinando as cenas, completamente separados do que continuava acontecendo na intervenção e, portanto, com um corte em seu fluxo do coletivo geral. Eles ficaram sem ouvir as músicas, que normalmente nesse trabalho estão ao fundo, assim como a plateia não viu os ego-atores combinando as cenas e se vestindo com fantasias e adereços cênicos.

O uso da música foi o nosso maior desafio nesse formato, pois a plataforma não é propícia para arte, e sim para palestras. As limitações quanto ao atraso da transmissão e da qualidade do som levaram a uma dinâmica diferente no uso da música no evento. Por um lado, a música deixou de ser um apoio à cena, na medida em que estava ausente nas esculturas fluidas e durante a encenação propriamente dita. Por outro lado, para além da prática usual das apresentações presenciais, forçou a explorar e utilizar possibilidades que o grupo não usava, ou usava pouco. Entre elas, o cantar $a$ capella, a declamação de textos das músicas como se fosse um poema, o uso de playback em vez do acompanhamento de instrumentos "ao vivo". Por outro lado, dá à música um papel diferente, menos estético na medida em que não participa das etapas "cênicas", mas proporciona uma nova força e novas possibilidades como elemento aglutinador e de ligação entre as etapas da atividade. Essas adaptações não representam necessariamente perdas, mas flexibilizações necessárias e criativas para um novo contexto. E, ao final, conseguimos um resultado muito satisfatório, tanto que a organizadora do projeto compartilhou ao final um texto, que produziu durante o evento, com parte das letras das músicas: 


\author{
DA PRIMEIRA CENA \\ A Rita levou \\ A ação cultural levou o próprio CCSP \\ o Covid-19 levou a saúde \\ O presidente levou a civilidade \\ As relações entraram na Barbárie \\ Mas não ficamos mudos \\ Nunca mais \\ Estamos aqui - VIVOS
}

DA SEGUNDA CENA

A fala é uma

A ação é outra

SER E AÇÃO

Aí a contradição

Quais os princípios que regem a civilidade? Os vínculos?

Somos todos iguais, braços dados ou não... Não sorrimos à toa

Estamos fazendo a hora?

\section{REFLEXÕES ESPECÍFICAS SOBRE A ADAPTAÇÃO AO AMBIENTE ON-LINE}

A realização de ensaios na plataforma permitiu desenvolver na equipe a necessária familiaridade com a ferramenta, não somente em seus aspectos tecnológicos, mas também nas diferenças quanto aos aspectos visuais e sonoros da linguagem. Questões como distância da câmera e a ocupação da tela com rosto ou corpo; uso da manipulação de objetos; produção de sons pelos atores; gerenciamento da música; sincronicidade entre atores.

Alguns aspectos da dinâmica usual de ensaios e reuniões da trupe, tais como o uso de emoções, cenas do próprio grupo para exercício e o processamento de cada exercício para rodar o ciclo de aprendizado e melhoria, foram mantidos.

Em relação à direção, é importante destacar a necessidade de um anfitrião/mediador, que faz a mediação da plateia com o uso da plataforma, num papel que se poderia chamar de “direção técnica”. Faz parte dessa função a atenção ao "bate-papo" (chat) escrito, uma vez que diversas solicitações vêm por este canal. Foi observado que é muito difícil para a direção exercer os dois papéis: o de mediação interpessoal e o de mediação da tecnologia, sem prejuízo da qualidade do trabalho. Em relação aos ego-atores, a estratégia de colocá-los em outra sala simultânea, no momento da combinação, enquanto a música faz a manutenção do aquecimento, permite que eles tenham o tempo para a elaboração e produção da cena.

Outra lição aprendida foi que o mecanismo de gerenciamento das janelas de vídeo da plataforma Zoom funciona de maneira diferente em computadores, em celulares ou tablets. Em função da plataforma exibir apenas quatro janelas nos celulares, sendo por padrão uma a própria janela do usuário do aparelho, optamos por ter apenas três ego-atores, diferentemente do presencial, que são quatro.

\section{CONSIDERAÇÕES FINAIS}

Vencendo preconceitos, descobrem-se novas possibilidades. Ao abrir-se para o novo, amplia-se o alcance das equipes de trabalho ao poder atuar e atender públicos de outras localizações geográficas, sem as amarras dos custos e das dificuldades logísticas. E há a possibilidade de formação de grupos com sociometrias diferentes, uma vez que a própria relação entre as pessoas tem naturezas e vivências diversas.

Possibilitar o encontro socionômico por meio da tecnologia e do TR de forma sensível, estética e cuidadosa pode, como vimos, ser um dispositivo importante no cuidado da Saúde Mental durante a quarentena. A intervenção psicodramática, em especial o TR, permitiu que cada um visitasse o outro a partir da sua janela virtual e revivesse, coletivamente, cenas que podem ser protagônicas do mundo ou apenas desse grupo em particular. E mesmo que seja só desse grupo, fez diferença para algumas pessoas, as quais agradeceram o momento de pausa para se reunirem e, ainda que individualmente, serem representadas. 
Ao superar as barreiras geográficas físicas e as barreiras psíquicas do distanciamento social, as intervenções podem, como foi o caso da nossa em particular, avivar a noção de pertencimento, de identificações e de coletivo durante a pandemia. Cada um pode se sentir parecido em momentos como esse de sofrimento mundial, a ponto de não se sentir enlouquecendo em sua solidão ou no seio familiar de exclusiva convivência, às vezes tão difícil. Isso pode ser considerado saúde, o pertencer!

Uma das propostas do TR é a busca pela sensação de pertencimento. E isso conseguimos atingir também on-line, como temos feito ao longo desses dezoito anos de experiência com grupos variados em instituições, empresas, órgãos públicos etc. E, assim, percebemos que esse tipo de intervenção de TR, desenvolvido dentro do momento necessário de afastamento social atual, pode ser um instrumento importante nas relações entre grupos corporativos e institucionais, com menor custo e maior abrangência geográfica.

Também abre possibilidade para trabalhos nesse formato com profissionais que se encontram em home office ou com profissionais de saúde, sofrendo por estar à frente do medo, contágio, estresse elevado nas decisões e ações numa crise como a que ainda estamos vivenciando.

Uma curiosidade: coincidências nessa modalidade de sociopsicodrama costumam ocorrer, de maneira mágica, principalmente, durante a intervenção. Algo que o narrador não disse e os atores colocam em cena. Mas, parece que fomos além. Apenas duas semanas depois da intervenção, um confronto com violência semelhante, reprimido pela polícia, se deu na Avenida Paulista. Uma antevisão desse sonhador ou uma captação desse clima coinconsciente?

\section{AGRADECIMENTOS}

Aos demais integrantes do Grupo Improvise que participaram do desenvolvimento da adaptação: Fernando de Vincenzo, Patricia Franco, Maria Andrea Ferraro Suplicy, Mairton Bezerra, Amauri Prates, Marco Tulio Garcia, Thais Trevizol, Luciana Souza Nakayama, e à participação especial de Helena Coutinho. A Mariângela Wechsler e ao grupo de usuários do CCSP, pelo convite e pela articulação da intervenção.

\section{CONTRIBUIÇÃO DOS AUTORES}

Todos os autores contribuíram igualmente para este artigo.

\section{REFERÊNCIAS}

Brito, V. (2006). Um convite à pesquisa: epistemologia qualitativa e psicodrama. In A. M. Monteiro, D. Merengué, \& V. Brito (Org.), Pesquisa qualitativa e psicodrama (pp. 13-56). São Paulo, SP: Ágora.

Brooks, S. K., Webster, R. K., Smith, L. E., Woodland, L., Wessely, S., Greenberg, N., \& Rubin, G. J. (2020). The psychological impact of quarantine and how to reduce it: rapid review of the evidence. The Lancet, 395, 912-920. https://doi.org/10.1016/ S0140-6736(20)30460-8

Féo, M. D, S. (2009). Direção socionômica multidimensional AGRUPPAA e a fé tácita no eterno retorno. Revista Brasileira de Psicodrama, 17(1), 87-104. Recuperado de https://revbraspsicodrama.emnuvens.com.br/rbp/article/view/85 
Fleury, H. J. (2020). Psicodrama e as especificidades da psicoterapia on-line. Revista Brasileira de Psicodrama, 28(1), 1-4. Recuperado de https://revbraspsicodrama.emnuvens.com.br/rbp/article/view/406

Freeman, D. (2019). Distributed embodiment across time and space: escape character's ongoing work on creating telepresence participatory experiences in Sparasso. Canadian Theatre Review, 178(1). Recuperado de https://ctr.utpjournals.press/doi/ suppl/10.3138/ctr.2019.178.issue-x

Gorman, T., Syrjä, T., \& Kanninen, M. (2019). There is a world elsewhere: rehearsing and training through immersive telepresence. Theatre, Dance and Performance Training, 10(2), 208-226. https://doi.org/10.1080/19443927.2019.1610491

Kaiser, R., Ursu, M. F., Falelakis, M., \& Horti, A. (2015, October). Enabling distributed theatre performances through multi-camera telepresence: capturing system behaviour in a script-based approach. In Proceedings of the 3rd International Workshop on Immersive Media Experiences (21-26). New York: Association for Computing Machinery. Recuperado de https://dl.acm.org/doi/ pdf/10.1145/2814347.2814351

Marcinko, D., Jakovljević, M., Jakšić, N., Bjedov, S., \& Mindoljević Drakulić, A. (2020). The importance of psychodynamic approach during COVID-19 pandemic. Psychiatria Danubina, 32(1), 15-21. https://doi.org/10.24869/psyd.2020.15

Mindoljević Drakulić, A., \& Radman, V. (2020). Crisis psychodrama in the era of COVID-19. Psychiatria Danubina, 32(1), $22-24$. https://doi.org/10.24869/psyd.2020.22

Rodrigues, R. (2016). Teatro de reprise: improvisando com e para grupos. São Paulo, SP: Ágora.

Ruiz, A. L., Arcaño, K. D., \& Pérez, D. Z. (2020). La psicología como ciencia en el afrontamiento a la COVID-19: apuntes generales. Anales de la Academia de Ciencias de Cuba,10(2). Recuperado de http://www.revistaccuba.cu/index.php/revacc/article/view/839 Salas, J. (2000). Playback Theatre: uma nova forma de expressar ação e emoção. São Paulo, SP: Ágora.

Tripp, D. (2005). Pesquisa-ação: uma introdução metodológica. Educação e pesquisa, 31(3), 443-466. http://doi.org/10.1590/ S1517-97022005000300009

Wechsler, M.P.F., \& Monteiro, R. F. (Orgs.) (2014). Psicodrama em espaços públicos: práticas e reflexões. São Paulo: Ágora. 